\title{
Overweight and Obesity in Physically Active Men in Punjab
}

\author{
Nishibha Thapliyal and Ashok Kumar
}

\begin{abstract}
Aim: The aim of the study was to measure overweight and obesity in physically active men in Punjab. Method: One hundred $(\mathrm{N}=100$, ) men with moderate physical activity between the ages 20-40 years were randomly selected. Each subject was measured for anthropometric parameters after taking valid consents. Results: The mean age, height and weight of men was $34.1 \pm 5.0$ year $172.7 \pm 3.7 \mathrm{~cm}$ and $71.6 \pm 5.7 \mathrm{~kg}$. About $29 \%$ of men were found to be overweight as per the BMI classification given by World Health Organisation (WHO). $77 \%$ of individuals showed Waist hip ratio (WHR) as 'substantially increased'. A strikingly high $67.5 \%$ (out of 77) of subjects who had normal BMI showed increased WHR. Conclusion: It was concluded that individuals with normal BMI also had high WHR ratio signifying the prevalence of high abdominal obesity in these men in Punjab. A high number of active individuals had high WHR indicating increase risk of developing chronic metabolic diseases. Intervention to control abdominal obesity is recommended.
\end{abstract}

Nishibha Thapliyal

Ph.D. Scholar

Department of Sports Science

Punjabi University (Patiala) Punjab, India.

Email: nishibhathapliyal@gmail.com

Ashok Kumar

Associate Professor

Department of Sports Science

Punjabi University (Patiala) Punjab, India.

Email: akashokin@gmail.com

\section{Key Words: BMI, WHR, WHO}

DOI: $10.18376 / j e s p / 2018 / v 14 / i 2 / 111301$

\section{Introduction}

Overweight and Obesity are defined as excessive accumulation of fat in the body that presents a health risk. (WHO) It is an epidemic that entire world is suffering from. Globally $39 \%$ of adults aged 18 years and above are overweight and about $13 \%$ obese (WHO factsheet 2016). This global rise in obesity has also affected India as well. India which was traditionally known for malnutrition earlier has also seen a rise in number of cases of overweight and obesity (Prentice 2006; Karala 2002; Chatterjee 2002). In India, according to the NFHS Survey 2005-2006, Punjab topped the list of the rate of obesity in entire India with $30.3 \%$ of males and $37.5 \%$ of female being obese followed by Kerala (NFHS 2005-06). Generally a person having body weight at least $20 \%$ higher than he/she should are considered as obese. Body Mass Index (BMI) is the most commonly used diagnostic tool to measure obesity but in Indians a unique trend in obesity is visible. Indians tend to gain excessive body fat in abdominal and subcutaneous regions (Kalara 2012). Hence BMI along with Waist Circumference and Waist Hip Ratio (WHR) are also needed to study the prevalence overweight and obesity in India as there are many reports suggesting that for a given BMI, Indians have higher or increased waist circumference (Ramachandran 2005). Often activity also plays an important role in the controlling weight but some studies have also observed that sometimes moderately active men may also become overweight or obese (Tjepkema 2006). In the present study overweight and obesity were measured in active men through various indices like BMI, Waist Circumference, Waist Hip Ratio etc as one indices may not indicate the true pattern of overweight and obesity. 


\section{Materials and Method}

One Hundred physical active men in the age group 20-40 years from Patiala, Punjab were randomly selected for present study. Random selection of samples was done in order to obtain genuine results and minimize bias. After the subjects were selected, each of them were measured for height, weight, waist circumference, hip circumference and other anthropometric parameters after taking their consents.

\section{Results \& Discussion}

The mean age, height and weight of men was $34.1 \pm 5.0$ year, $172.7 \pm 3.7 \mathrm{~cm}$ and $71.6 \pm 5.7 \mathrm{~kg}$. The mean body mass index (BMI) of physical active men was $24 \pm 1.8 \mathrm{~kg} / \mathrm{m}^{2}$ which was normal as per WHO norms (Table 2). In the present study, when we observed an individual BMI of the hundred subjects then it was found that BMI of $71 \%$ subjects $(n=71)$ fell under the normal weight category and $29 \%$ were found to be overweight when compared with norms of WHO (Table 2). Further, out of the 71 men whose BMI fell under the normal weight category, $66 \%$ of them were in the range of 22.5 to 24.99 category which was under observed risk category as per WHO Expert Consultation BMI for Asian population (WHO Expert Consultation, 2004) (Table 3). The 29\% overweight subjects were found to be high risk category as per WHO Expert Consultation BMI for Asian population (WHO Expert Consultation, 2004) (Table 3).

Table 1. Mean \pm SD of age, height, weight, and BMI of Physically Active men

\begin{tabular}{|l|l|}
\hline Variable(s) & Mean \pm SD \\
\hline Age $($ year $)$ & $34.1 \pm 5.0$ \\
\hline Height $(\mathbf{c m})$ & $172.7 \pm 3.7$ \\
\hline Weight $(\mathbf{k g})$ & $71.6 \pm 5.7$ \\
\hline Body Mass Index $\left(\right.$ BMI) $\left(\mathrm{kg} / \mathbf{m}^{2}\right)$ & $\mathbf{2 4} \pm 1.8$ \\
\hline Waist circumference $(\mathrm{cm})$ & $\mathbf{8 3 . 9} \pm 5.4$ \\
\hline Hip circumference $(\mathbf{c m})$ & $90.4 \pm 5.1$ \\
\hline Waist-to-hip ratio $($ WHR) & $\mathbf{0 . 9} \pm \mathbf{0 . 1}$ \\
\hline
\end{tabular}

Table 2. BMI as per WHO

\begin{tabular}{|l|l|}
\hline BMI $\left(\mathbf{k g} / \mathbf{m}^{2}\right)$ category & Percentage \% \\
\hline$<\mathbf{1 8 . 5 0}$ (Underweight) & $\mathbf{0 \%}$ \\
\hline $\mathbf{1 8 . 5 - 2 4 . 9 9}$ (Normal) & $\mathbf{7 1 \%}$ \\
\hline $\mathbf{2 5 . 0 0}$ ( Overweight) & $\mathbf{2 9 \%}$ \\
\hline
\end{tabular}

Table 3. WHO Expert Consultation-Appropriate BMI for Asian population

\begin{tabular}{|l|l|}
\hline BMI $\left(\mathbf{k g} / \mathbf{m}^{2}\right)$ category & Percentage \% \\
\hline$>\mathbf{1 8 . 5 0 - 2 2 . 5}$ (Normal) & $\mathbf{3 4 \%}$ (out of 71) \\
\hline 22.5-24.99 (observed risk category) & $\mathbf{6 6 \%}$ (out of 71 \\
\hline 25.00- 31.0 ( high risk category) & $\mathbf{2 9 \%}$ \\
\hline
\end{tabular}


The mean waist circumference, hip circumference and waist-hip ratio were found to be $83.9 \pm 5.4 \mathrm{cms}, 90.4 \pm 5.1 \mathrm{~cm}$ and $0.9 \pm 0.1$. The Waist Circumference of only $4 \%$ of the men was found elevated but when the Waist Hip Ratio of the same men were calculated, then about 77 subjects as per the WHO guidelines fell under the 'increased risk category' of obesity and its effecting disorders (Obese category as per W.H.O guidelines) (Figure1). No one was found in the high risk category. The presence of such high number of population in the 'increased risk category', poses an increased risk of developing chronic diseases like diabetes, hypertension, cardiovascular diseases and metabolic syndrome (Yusuf et al 2004; Schorr et al 1998). The high WHR ratios are also indicators of presence of abdominal obesity.

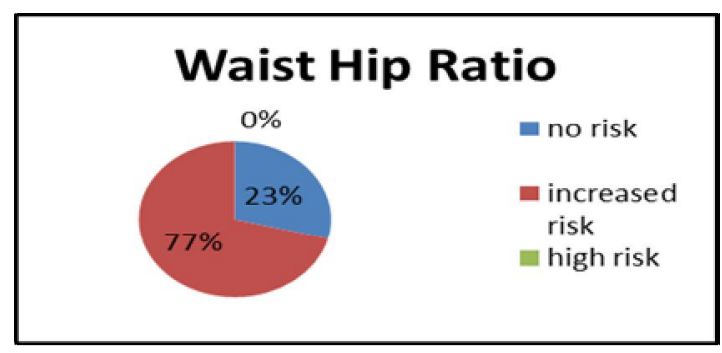

Figure 1. Waist Hip Ratio of men

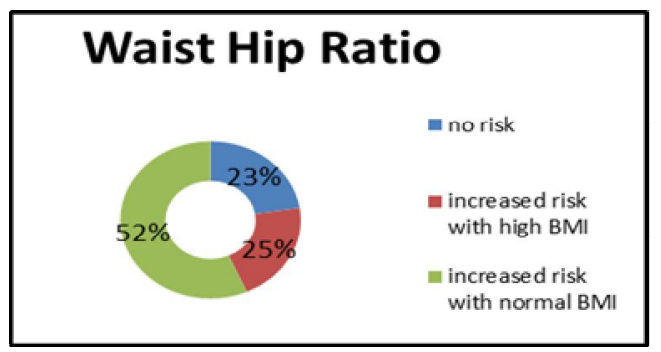

Figure 2.Waist Hip Ratio in accordance to BMI

It was also observed that, out of the 77 subjects who fell in' increased risk category' according WHO guidelines, 52 of subjects had normal BMI. (Figure 2) This shows that WHR along with BMI is essential for observing overweight and obesity especially abdominal obesity in individuals; as BMI alone might not give true status of the obesity levels of individuals. (Wellborn \& Dhaliwal 2007; Harald et al 2007; Nayamdorj 2008).

The body fat $\%$ was also calculated and according to the American Council of Exercise ACE body fat chart, only $37 \%$ of individuals fell under the 'athlete's category'. $50 \%$ i.e. half of the subjects fell under the 'fit category' and only $8 \%$ under 'average category'. This signifies that individuals who involved in activity at a regular basis are able to maintain their body fat (Thremblay et al. 1990). 


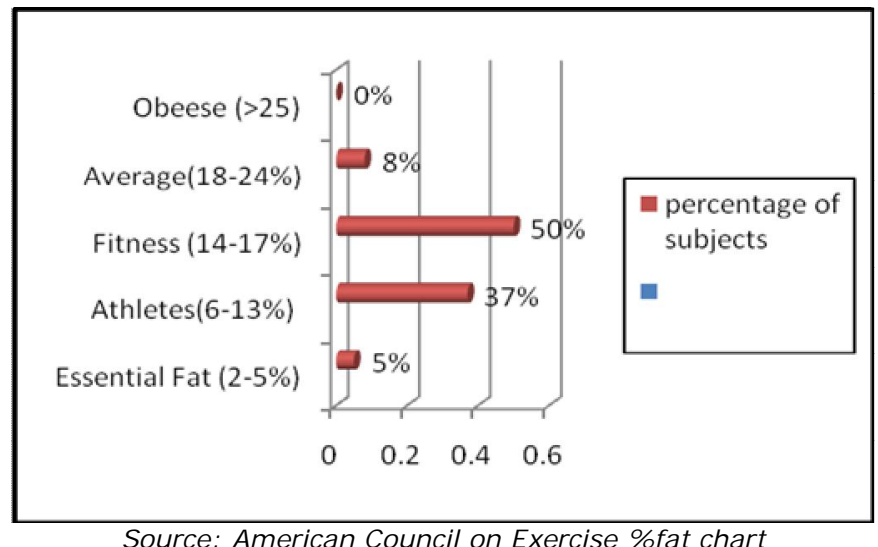

Figure 3. Body Fat\% of men

\section{Conclusion}

There is a high prevalence of 'abdominal obesity' in men in Punjab. Also a high number of individuals are at an increased risk of developing overweight and obesity issues. These men also have an increased predisposition in attaining other metabolic disease like diabetes, hypertension, CVD and other non communicable diseases as reflected by increased WHR's. It is also concluded that WHR along with BMI should be taken as a variable to measure overweight and obesity in individuals as BMI alone may not give the true status. Also since these individuals are exercising on a regular basis and still have abdominal fat deposition then special dietary alterations may be needed for them.

\section{References}

Chatterjee P (2002); India sees parallel rise in malnutrition and obesity. Lancet; 360(9349):1948.

Harald J. Schneider, Heide Glaesmer, Jens Klotsche, Steffen Böhler, Hendrik Lehnert, Andreas M. Zeiher, Winfried März, David Pittrow, Günter K. Stalla, Hans-Ulrich Wittchen (2007); Accuracy of Anthropometric Indicators of Obesity to Predict Cardiovascular Risk, The Journal of Clinical Endocrinology \& M etabolism, Volume 92, Issue 2, Pages 589-594,

Joshi SR. (2003); Metabolic syndrome - Emerging clusters of the Indian Phenotype. J Assoc Physicians India; 51: 445-6.

Kalra S,Unnikrishnan A.G, (2012); Obesity in India: The weight of the nation. J med Nutr Nutraceut ;1:37-41

Nayamdorj R, 2008; BMI Compared With Central Obesity Indicators in Relation to Diabetes and Hypertension in Asians. Obesity a research journal Volume16, Pages 1622-1635

Prentice Andrew M (2006); The emerging epidemic of obesity in developing countries, International Journal of Epidemiology, Volume 35, Issue, Pages 93-99

Ramachandran A, Snehalatha C, Viswanathan V, Viswanathan M, Haffner SM, (1997); Risk of noninsulin dependent MOHAN \& DEEPA : OBESITY \& ABDOMINAL OBESITY IN ASIAN INDIANS 595 diabetes mellitus conferred by obesity and central adiposity in different ethnic groups: a comparative analysis between Asian Indians, Mexican Americans and Whites. Diabetes Res Clin Pract; 36: 121-5.

Schorr U, Blaschke K, Turan S, Distler A, Sharma AM, (1998); Relationship between angiotensinogen, leptin and blood pressure levels in young normotensive men. J Hypertens; 16: 1475-80 


\section{Journal of Exercise Science \& Physiotherapy Vol. 14 No. 2 (July to December) 2018 \\ ISSN: 0973-2020 (Print) I I OR Impact Factor =6.115 UGC Approved [no.7485] ISSN: 2454-6089 (Online)}

The Asia Pacific perspective: Redefining obesity and its treatment. Regional Office for the Western Pacific of the World Health Organization. World Health Organization, International Association for the Study of Obesity and International Obesity Task Force. Health Communications Australia Pty Limited, St Leonards, Australia; 2000 p. 22-9.

Third National Family Health Survey. International Institute for Population Sciences, 2005-2006, Mumbai; http:// nfhsindia.org/nfhs3_national_report.html

Tjepkema, Michael. 2006; Adult obesity Health Reports Vol. 17, Iss. 3: 9-25.

TremblayA, J P Després, C Leblanc, C L Craig, B Ferris, T Stephens, C Bouchard (1990); Effect of intensity of physical activity on body fatness and fat distribution, The American Journal of Clinical Nutrition, Volume 51, Issue 2, Pages 153-157

Wellborn T.A \& Dhaliwal S.S, (2007); Preferred clinical measures of central obesity for predicting mortality European Journal of Clinical Nutrition volume 61 1373-1379

WHO expert consultation. (2004) Appropriate body-mass index for Asian populations and its implications for policy and intervention strategies. Lancet; 363: 157-163

Yusuf Salim, Steven Hawken, Stephanie Ôunpuu, Tony Dans, Alvaro Avezum, Fernando Lanas, Matthew McQueen, Andrzej Budaj, Prem Pais, John Varigos, Liu Lisheng, (2004); Effect of potentially modifiable risk factors associated with myocardial infarction in 52 countries (the INTERHEART study): case-control study, The Lancet, Volume 364, Issue 9438, Pages 937-952,ISSN 01406736.

Conflict of Interest: None declared 